\title{
THE TRANSACTIONAL ASSETS PRICING APPROACH AND INCOME CAPITALIZATION MODELS IN PROFESSIONAL VALUATION: TOWARDS A "QUICK" INCOME CAPITALIZATION FORMAT
}

\author{
Vladimir B. Michaletz, Ph.D. Eng. \\ Russian Society of Appraisers \\ e-mail:mihail-mmm@mail.ru \\ Andrey Artemenkov, Ph.D., MRICS, (Israel) \\ International Valuation Centre (IVC) \\ State University of Management \\ e-mail: achudakhin02@gmail.com
}

\begin{abstract}
The transactional assets pricing approach within valuation theory (TAPA) reviewed in this paper and developed by the authors, now more than a decade ago (MICHALETZ, ARTEMENKOV A. \& ARTEMENKOV L., (2007), has found many applications in professional valuation practices dealing with illiquid assets (LEYFER 2006; ANDREWS 2011)). Consequently, challenges have arisen to ascertain its performance and develop tools, on its basis, which can be employed by valuers in their everyday practice and which are aligned as much as possible with the income approach tools used by them in their professional work. This paper proposes modifications to the standard direct income capitalization technique to align it as closely as possible with the results derivable under the applications of the TAPA basic pricing formula. The authors develop the respective adjustments using the Taylor series expansion and then, using a simulation technique, outline the performance of the resulting modified ("quick") income capitalization model against the TAPA benchmark. The findings indicate that such a modified ("quick") income capitalization approach has reasonable accuracy, which makes it amenable to direct usage in valuation practice, given the described assumptions.
\end{abstract}

Key words: Transactional Assets Pricing Approach, discount rates, Direct income capitalization, Gordon growth model, Inwood model, Ring model, Professional Valuation.

JEL Classification: D46, D49, G12.

Citation: Michaletz V. B., Artemenkov A., 2018, The Transactional Assets Pricing Approach and Income Capitalization Models in Professional Valuation: Towards a "Quick" Income Capitalization Format, Real Estate Management and Valuation, vol. 26, no. 1, pp. 89-107.

DOI: $10.2478 /$ remav-2018-0008

\section{Introduction}

The structure of this paper is as follows: In Section 1, we review a mathematical formulation for the "transaction equilibrium" and "fair exchange" principles (as applied to values-in-exchange situations), which are now essentially incorporated into the equitable value basis of valuation under the International Valuation Standards (IVS) 2017 edition (IVSC (2017)). The social and economic importance of these principles is more extensively described elsewhere (see GALASYUK 2016; ARTEMENKOV 2017). Section 2 reviews the logic and mechanics of discount rates under the framework 
of the transactional assets pricing approach (TAPA). Like the approach itself, it aims to deal with the general case, therefore, time-variant discount rates are introduced and their aggregation to a portfolio ("opportunity investment") level is shown. Section 3 is the main section, which modifies the general transactional assets pricing approach and discusses its particular applications, typecasting them in such traditional forms as the Gordon, Inwood and Ring models formulated from the standpoint of transactional equilibrium conditions (instead of more conventional derivations based on the standpoint of a particular investor). We delve deeper into the direct income capitalization technique and discuss some straightforward adjustments that can be proposed to it to significantly broaden the scope of its applicability. The resulting modified model (the "quick" income capitalization technique) has been tested by us via simulations against the TAPA general pricing formula benchmark -- with satisfactory findings asregards its accuracy. Section 4 concludes the work.

\section{Fair valuation principles underlying the transactional assets pricing approach}

The novelty of the transactional assets pricing approach (MiCHALETZ, ARTEMENKOV, ARTEMENKOV 2007) is in that it recasts the basic derivations of valuation theory models proceeding from a transaction-based perspective (i.e. the interests of both transacting parties - buyer and sellerexplicitly feature in the formulations of valuation theory models, as opposed to the conventional specific investor-based standpoint/orientation found in such classical works as FISHER (1930) or reference sources such as FRIEDMAN and ORDWAY (1989)). The essence of the transactional assets pricing approach (TAPA) thus lies essentially in reconstituting the conventional valuation models $(D C F+$ capitalization models, such as: Gordon, Ring and Inwood) on the basis of transactional principles, rather than traditional Investment theory principles. In lieu of implications from a singular specific-investor basis, a holistic transactional view (involving both transacting agents) is substituted (GALASYUK 2016).

Such a transactional view proceeds from the following model situation. Assuming that an agent owns an asset that annually yields the net operating income $N O I_{i}$. $(\mathrm{i}=1 . . \mathrm{n}$ years), should the agent be inclined to dispose of the asset, the agent's natural interest is not to be the losing party in the transaction. This means that they will sell their asset on the condition that the proceeds they receive in the transaction are capable of generating the same amount of capital in the future as the combined option of (1) keeping the asset to themselves and thus earning a future stream of NOI $i$. and (2) having the right to sell the asset sometime in the future (in the year $n$ ) over its economic life. (i.e. the principle of equivalence of interests or "the principle of fair exchange").

Thus, both potentially transacting agents - the seller and the buyer - will regard the following "transactional equilibrium" condition as equitable:

$$
S_{n}^{s}=S_{n}^{b}
$$

where: $S_{n}^{S}$-is the amount of capital in an "Investment medium"1 of the selling agent ("seller") in Year $n$ after the proceeds $P V$ from the disposal of the asset have been deposited into it; and $S_{n}^{b}$-stands for the amount of capital in Year $n$ accumulated by the counterparty (buyer) as the result of ownership interest in the purchased asset (the sum of their future NOIs up until Year $n$ which they reinvest into their "Investment medium" plus the terminal value of the asset in Year $n$ which can be converted into cash).

If the considered transaction takes place, a prudent seller will invest their transaction proceeds $P V$ into an "investment medium", or portfolio, of his choice, where the proceeds will start accumulating due to reinvestments of the accrued annual interest (yield) up until Year $n$ :

\footnotetext{
1 The notion of an "investment medium" implies an appealingly profitable and equally accessible investment opportunity to both parties to the transaction (a bank deposit, setting up a new business, investing in a securities portfolio, real property, reinvesting back into the expansion of the business with the subject asset etc., or the mixture of all these options, i.e. an investment portfolio). Another kindred term is the notion of "Investment opportunity", one that I. Fisher uses in his "Theory of Interest" (1930), though in a more specific context laden with optionality considerations.
} 


$$
S_{n}^{s}=P V \prod_{i=1}^{n}\left(1+r^{s}(i)\right)
$$

where: $r^{s}(i)$ - is the annual rate of interest (or yield) for year $i,(0<i \leq n)$ arising from the sellers' "investment medium".

A prudent buyer is able to obtain similar investment advantages by investing into their "investment medium" their annual operating income $\mathrm{NOI}_{i}(0<i \leq n)$ arising from the purchased subject asset, so that their capital $S_{n}{ }^{b}$ by the end of Year $n$, along with the Terminal value of the asset now in their possession $S_{\text {res }}$, equals:

$$
\begin{aligned}
& S_{n={ }_{k=1}^{b}}^{n} N O I_{k} \prod_{i=k+1}^{n}\left(1+r^{b}(i)\right)+S_{r e s}= \\
& =N O I_{1} \cdot\left(1+r^{b}(2)\right) \cdot\left(1+r^{b}(3)\right) \cdot \ldots \cdot\left(1+r^{b}(n)\right)+ \\
& +N O I_{2} \cdot\left(1+r^{b}(3)\right) \cdot\left(1+r^{b}(4)\right) \cdot \ldots \cdot\left(1+r^{b}(n)\right)+\ldots \\
& +N O I_{i} \cdot\left(1+r^{b}(i+1)\right) \cdot\left(1+r^{b}(i+2)\right) \cdot \ldots \cdot\left(1+r^{b}(n)\right)+\ldots+N O I_{n}+S_{r e s},
\end{aligned}
$$

where $r^{b}(i)$ is the rate of interest (yield) applicable to the buyers' investments into their "medium".

By combining expressions (1.1), (1.2) and (1.3), we can derive, through the "transaction-based perspective", a value-in-exchange for the asset which is "fair" / "equitable" from both the buyer's and the seller's standpoints:

$$
P V=\frac{\sum_{k=1}^{n-1} N O I_{k} \prod_{i=k+1}^{n}\left(1+r^{b}(i)\right)+N O I_{n}}{\prod_{k=1}^{n}\left(1+r^{s}(i)\right)}+\frac{S_{r e s}}{\prod_{k=1}^{n}\left(1+r^{s}(i)\right)}
$$

The rates of return $r^{s}(i)$ and $r^{b}(i)$ may not match perfectly, for the probability that both the seller and buyer will invest their proceeds/income in exactly the same way, with similar interest accruing to them, is not very high. But if a willing and able buyer and seller enter into transaction on arm's-length terms, and both parties have reasonable knowledge of the relevant facts, it is, by no means, unreasonable to suggest that the rates of return pertaining to both parties will tend to converge to certain most likely estimates that characterize the "investor niche" where the transaction occurs. This in turn implies that the market value of an asset is determined by most likely buyers and sellers ${ }^{3}$ that we can ourselves conceive of as having proper knowledge of the market ("investor niche") (or of the presumed parties that would most likely commit themselves to the transaction), and such a "hypothetical transaction view" is well-aligned with the international definitions of market value (enshrined, for example, in the international valuation standards 2017 (IVSC, 2017)). Are there any differences between "the most likely buyers and sellers" when it comes to the question of their respective investment strategies and the expected rates of return $r^{b}(i)$ and $r^{s}(i)$ that those can generate?

Two opposing views admit themselves. First, the differences can exist for the reason that the seller, after the transaction occurs, is in the possession of considerably more liquidity/money than the buyer who can only count on his future NOIs as the object of re-investment. If a valuer sticks to this view, he or she should determine (as presented in (1.4)) the current exchange value of an asset $(P V)$ by considering and forecasting (differing) future rates of return germane to both the buyer and the seller. Formula (1.4), thus, represents the general case and is a novel contribution of the transactional assets pricing approach to the toolset of valuation theory. The second opposite view is that the difference in the rates of return is immaterial, and all the avenues of reasonable investment strategies are open for both the buyer and the seller to pursue. Both settle for the optimal reinvestments with regard to $P V$ and NOI amounts that agents of their circle deem most rewarding and practicably follow. This view

\footnotetext{
$2 \prod_{i=1}^{n}\left(1+r^{s}(i)\right)$ means the product (chain multiplication) of the yields for each year, from 1 st to $n$-th, i.e. the expression (1.2) can be recast as: $S_{n}{ }^{s} P V((1+r(1)) *(1+r(2)) *(1+r(3)) * \ldots *(1+r(n)))$

3 "Market value... being the most probable price reasonably obtainable in the market by the buyers and sellers..." (THE INTERNATIONAL VALUATION STANDARDS 2017, STANDARD 104).
} 
implies that valuers should have no reason to deduce that the rates $r^{s}(i)$ and $r^{b}(i)$ differ from each other significantly. Making the assumption that both rates are uniform: $r^{s}(i)=r^{b}(i)=r(i)$ and after appropriate substitutions, we conclude that Formula (1.4) can be simplified and converted into the following:

$$
P V=\sum_{k=1}^{n} \frac{N O I_{k}}{\prod_{i=1}^{k}(1+r(i))}+\frac{S_{r e s}}{\prod_{i=1}^{n}(1+r(i))}
$$

This is the well-known formula always used in DCF analysis/calculations ${ }^{4}$, though its justification is more often formulated axiomatically from the principle of anticipation or the investment worth paradigm (or deduced from the relational definition of discount rate in a static perfect market setting, as in Miller \& Modigliani (1961)'s Formulas (1)-(10) ), rather than from the "transactional equilibrium based view" proposed above, which places Formula (1.5) as a specific case of a more general Formula (1.4) situation.

Leaving the general "Formula (1.4)" case aside, we shall further pursue the deductions resulting from the considerations of the "Formula (1.5)" setting.

The uniform rate of return $r(i)$ in Formula (1.5), by its nature, is nothing else but the proverbial discount rate, and it is fair to say that there exists no other element in professional asset valuation more "mystifying" than that. It follows from our discussion that the discount rate for the exchange valuation of (illiquid) assets is, by its nature, dependent on, and firmly linked to, the ex ante rate of return on investment portfolio which the most likely buyers/sellers of the subject illiquid asset are judged to form. These portfolios can either be "broad", diversified and composed of, or linked to, a broad liquid market, or not. Which markets to enter and what investment mix of investors' portfolios to consider in the calculations of market (or equitable) value is a situational issue (one that depends on the available information, facts and judgments on the current state of the market), and will be briefly discussed further on. Here, however, it is important to understand the nature of the discount rate $r(i)$ and how it can be derived from the pricing behavior of prudent buyers and sellers under the proposed "transaction-based view".

\section{Developing individual and portfolio discount rates in the context of transactional asset pricing approach}

As established in the preceding section, the discount rate $r(i)$ - is the rate of return (in Year i) for investment media/portfolios of presumed (most likely) buyers and sellers of the subject asset, if they operate in the same environment and are able to transact on the same markets accessible to both parties.

\subsection{Single-period model}

It is not difficult to conceptualize a discount rate in a one-period model. In extension of (1.5), a fair transaction $s$ will only take place if the capital-appreciation expectations of both the seller and the buyer (the initial capital amount exchanged in their transaction is the $P V$ itself) are projected to be satisfied to the same effect:

$$
P V_{s}+\Delta P V_{s}+N O I_{s}=P V_{s} \cdot\left(1+r_{s}\right) .
$$

For the buyer, this means that their overall annual return from the subject asset is the combined effect of the appreciation (or depreciation) in the value of the asset $\triangle P V_{s}$ and the operating income $\mathrm{NOI}_{s}$ generated by the asset during the year.

As for the seller, a similar notion is also true. Assuming that they invest their proceeds $P V s$ from Transaction $s$ into stocks, their return over the next year will, therefore, come in two forms: appreciation (or fall) in the value of the stocks plus the dividend received. However, in specific cases (such as when dealing with instruments that are not income-generating, namely gold or commodities)

4 It is often the case that the DCF framework uses constant discount rates in the denominators of the terms, instead of time-variable ones. Therefore, in such specific instances the time factor enters as an exponent in the denominators of the formula terms, not as a direct multiplication string, as presented here. In this Paper, however, we aim to illustrate the general case of the DCF framework and will simplify it further in the subsequent sections of the Paper. 
$N O I_{s}$ might be left out from the reasoning framework (2.1) of the participant in Transaction $s$. The expression (2.1) allows to visualize the general meaning of the discount rate and the ways in which it can occasion the capital appreciation of the parties.

Dividing the right- and left-hand side of the equation (2.1) by $P V_{s}$, we derive the discount rate $r_{s}$, or the rate of return implicit in the subject asset $s$ that changes hands in the transaction between a presumed buyer or seller or in an asset within the investment portfolio of the presumed buyer/seller of the subject asset. By virtue of their function in pricing, we demonstrated that both rates are of a similar nature, only one is used to discount and the other is employed to compound the capital. Thus:

$$
r_{s}=\frac{N O I_{s}}{P V_{s}}+\frac{\Delta P V_{s}}{P V_{s}}=R_{s}+v_{s}
$$

Where by $R_{s}$ we denote no other than the income yield (which is further referred as "yield ratio"), that characterizes the income-generating capacity of an asset expected from it over the first period, and $v_{s}$ is the expected growth rate in the value of the asset (positive or negative).

One often comes across the expressions (2.1) or (2.2) in valuation and financial theory texts (see, for example, PRATT, REILLY and SCHWEIHS (2000, p. 160). According to RUBENSTEIN (2003), the expressions are originally traceable to Myron Gordon and Eli Shapiro, by whom they were popularized in the presented form among the investment profession in the mid-50s of the last century. But most of such texts do not usually elaborate the discount rates beyond the basic concept manifested in the presented one-period formulation (i.e. Formulas 2.1 and 2.2), so extending it to cover more periods (as in the next subsection 2.2.) would yield some interesting findings. We note here that such an extension might make the model directly applicable in practice since it would offer a reasoning framework which will allow for the forecasting of discount rates related to future periods. In contrast, one-period models such as (2.1) and the capital asset pricing model (CAPM) (SHARPE 1964) are, in fairness, devoid of direct practical forecasting and professional valuation capabilities ${ }^{5}$, since the DCF technique is inherently a multi-period one and doesn't square well with one-period-only forecasts.

If we are to, once again, look through the equations above, we may realize that the properties of investment opportunities ("investment media") available to a hypothetical seller and buyer transacting in Subject Asset $s$ may somehow differ from those that are peculiar to the asset $s$ in itself: There is no rule that says that investors into subject assets should only deal exclusively with assets similar in nature to those subject assets, and some investors prefer to diversify away their risks, while, in fairness, there are some (this is especially the cas with small-time unlisted business owners ) that tend to specialize ${ }^{6}$. Valuers, therefore, should consider, in their valuation framework (especially for illiquid assets), only the projections of the rates of return observable for investment media of presumed (most likely) investors into the subject asset. If the portfolios in question are broad and liquid enough, the task becomes easier, for the data and projections for some broad or narrow market index can be utilized directly; in other cases, some sort of "judgmentally-soft" guesswork might be necessary (which might be helped by the portfolio averaging schemes developed below, e.g. in expressions (2.3)-(2.6)). We would like to stress, however, that the discount rates, in general, are the properties of the expected performance of investment portfolios of presumed buyers/sellers of subject assets. Investments, of which such portfolios are thought to be composed, can be diversified and liquid, and put together on the principles of modern portfolio theory, or the portfolio can consist solely of the subject illiquid asset (for an undiversified investor). There are all kinds of variations in between these two extremes, and we cannot offer any normative theory of portfolio formation ${ }^{7}$, as we observe that, in many instances and sectors, buyers and sellers of (especially illiquid) assets follow a diversity of practices with respect to the composition of their investment portfolios.

\subsubsection{Portfolio principle in the single-period model}

So, the consideration of the performance of investment portfolios of presumed buyers and sellers of

\footnotetext{
5 Note the manifold "adjustments" usually introduced to CAPM results when the CAPM model is used for forecasting purposes, e.g. see MERCER (2004), SLEE (2004).

${ }^{6}$ Different styles, and modern philosophies, of property portfolio management have been discussed in recent times, for example, in MUCZYNSKI (2015).

7 Such as the CML and "efficient set", which are good ideas for selecting and combining liquid investments in active markets, as we believe that such markets are generally efficient.
} 
subject assets is an issue which is not straightforward, just like the derivation of the discount rates for such assets. Since, especially for work on inefficient markets, we cannot fall back on any established normative theory in this area, a lot will depend on the judgments of a professional valuer. In some cases, they might feel inclined to analyze the performance of the portfolio from the "bottom-up", as we would now describe it, by extending the principle incorporated in Equation (2.2) to cover the whole investment portfolio structure of the most likely ${ }^{8}$ buyers and sellers of the subject asset:

$$
\sum_{s=1}^{n} P V_{s}+\sum_{s=1}^{n} \Delta P V_{s}+\sum_{s=1}^{n} N O I_{s}=\sum_{s=1}^{n} P V_{s}+\sum_{s=1}^{n} P V_{s} \cdot r_{s}
$$

In respect to (2.3), it should be noticed that, if the assets (investments) $1 . . n$ of which the investment portfolio is composed are liquid and quoted on efficient markets, establishing the value $(P V)$ of them is not a problem (as it can be taken directly from their current market quotations). Otherwise, the task of deriving the value of illiquid assets becomes that of circular equations (unless crude estimates for $P V s$ of assets within the portfolio (including the subject illiquid asset) are adopted).

It should be stressed that the estimate of the rate of return for the overall portfolio of the likely investor holds the conceptual primacy for us in gauging discount rates for individual illiquid assets of the investor being valued for purposes of determining their values-in-exchange (given that $r^{s}(i)=$ $r^{b}(i)=r(i) ; \mathrm{i}=1$ ) (Of course, a specific rate of return on the subject asset contributes to the magnitude of the portfolio-related rate of return, since subject assets might form a substantial part of the portfolio of likely investors into them. But how does onecalculate this uniform portfolio-related representative rate $(r)$ out of the assortment of projected $r_{s}$ for assets within the portfolio? How do we average those $r_{s}$ ?

It is clear that the portfolio-level discount rate $r$ that we decide upon should be such as to satisfy the balance in (2.3):

$$
\sum_{s=1}^{n} \Delta P V_{s}+\sum_{s=1}^{n} N O I_{s}=\sum_{s=1}^{n} P V_{s} \cdot r_{s}=\sum_{s=1}^{n} P V_{s} \cdot r
$$

For practical calculations, by dividing both sides of the expression (2.4) by the overall current value of the portfolio, we derive the needful $r$ :

$$
r=\frac{\sum_{s=1}^{n} P V_{s} \cdot r_{s}}{\sum_{s=1}^{n} P V_{s}}=\frac{\sum_{s=1}^{n} N O I_{s}}{\sum_{s=1}^{n} P V_{s}}+\frac{\sum_{s=1}^{n} \Delta P V_{s}}{\sum_{s=1}^{n} P V_{s}}
$$

On the other hand, the discount rate $r$, as we established from Expression (2.2) and as is readily apparent in (2.5), is the sum of the portfolio yield ratio and the projected future (one-period) growth in the overall value of assets/investments in the portfolio:

$$
r=\sum_{s=1}^{n} \alpha_{s} \cdot r_{s}=R+v
$$

where $a_{s}$-is the value-proportioned weight (implicit in the middle part of Expression (2.5)) attaching to the projected rates of return for individual assets in the portfolio; $R$-is the portfolio yield ratio; and $v$ - the expected change in the total value of assets/investments in the portfolio.

It follows from Expression (2.6) that the (portfolio) discount rate $(r)$ will coincide with the (portfolio) yield ratio $(R)$ if the portfolio has no growth in the overall value of its assets projected for it (i.e. when $\mathrm{v}=0$ ).

One way to make sense of the presented rate of return/discount rate model is to regard it as a model interpreting the concept of discount rate as one of the rate of return available on alternative investments ("the opportunity cost of capital")9. Thus, one of the findings of the above discussion,

\footnotetext{
8 All references to most probable or most likely participants here can be construed in the light of the relevant guidance contained in the International Valuation Standards (e.g. Standard 104 in the IVS 2017 set)

${ }_{9}$ Like in CAPM (SHARPE 1964), we rely on the portfolio principle, but our discount rate model aims to be descriptive of the portfolios that tend to be formed by presumed (or typical) buyers/sellers of subject assets, rather than being based on any normative portfolio theory like CAPM.
} 
which we believe has a conventional ring to it, is that the most credible discount rate for valuing a subject asset - one which we should employ in a value-in-exchange valuation - is the one that represents an anticipated rate of return on a portfolio of a likely investor into the subject asset, not one that immediately relates to the subject asset's own performance features. But the two can be identical, or close to each other, if the agent in question is undiversified, or if all investment portfolio segments are similar in terms of their projected profitability and growth prospects.

\subsection{Multi-period discount rate projection model}

A more thorough attempt to project discount rates for the future and render the spirit of our approach truly compatible with the forward-looking nature of the DCF methodology means that a multi-period model of deriving discount rates should also be presented. We can no longer be content with the averaging of projected one-period portfolio returns as we have just done. Nevertheless, we do not relinquish the portfolio principle introduced above - for informed guesses about subject assets' buyers' and sellers' portfolios are inherently better for equitable valuation of these subject assets than their own (i.e. the subject assets') individual performance projections ${ }^{10}$.

To establish the discount rates for periods that lie ahead, we consider the following framework of changes in the value and derivable income for a specific asset $s$.

$\mathbf{1}^{\text {st }}$ period after the asset has been purchased in a transaction. At the end of this period the investors' capital will have changed due to the receipt of their first NOI installment from the asset and appreciation (depreciation) in the value of the asset:

$$
P V_{s} \cdot\left(1+v_{s}(1)\right)+N O I_{s} \cdot\left(1+u_{s}(1)\right)=P V_{s} \cdot\left(1+r_{s}(1)\right)
$$

where: $v_{s}(1)$ - is the expected rate of change in the value of the asset in the first period; $u_{s}(1)-$ is the expected rate of change in the amount of NOI receivable in the $1^{\text {st }}$ period (in Expression (2.7) it is always zero, for the investor receives his first NOI in Period 1, and he has no past period to benchmark it against to compute the rate. Thus, NOI received in the first period becomes the benchmark NOI itself), and $r_{s}(1)$ is the asset-specific rate of return pertaining to the first period (analogous to (2.1)).

Second period. The amount of capital accumulated at the beginning of the second period (Expression 2.7) is now the benchmark against which to compute the change (increase or decrease) in that capital expected in the second period:

$$
P V_{s} \cdot\left(1+v_{s}(1)\right) \cdot\left(1+v_{s}(2)\right)+N O I_{s} \cdot\left(1+u_{s}(1)\right) \cdot\left(1+u_{s}(2)\right)=P V_{s} \cdot\left(1+v_{s}(1)\right) \cdot\left(1+r_{s}(2)\right)
$$

where $r_{s}(2)$ is the asset-specific rate of return related to Period 2.

Period $i$. By induction we establish a similar way to calculate an asset-specific rate of return $r_{s}(i)$ related to period $i$ :

$$
P V_{s} \cdot \prod_{j=1}^{i}\left(1+v_{s}(j)\right)+N O I_{s} \cdot \prod_{j=1}^{i}\left(1+u_{s}(j)\right)=P V_{s} \cdot \prod_{j=1}^{i-1}\left(1+v_{s}(j)\right) \cdot\left(1+r_{s}(i)\right)
$$

\subsubsection{The portfolio principle in the multi-period model}

Referring to our discussion in Section 2.1 above that the discount rate in asset valuation is generally a concept reflecting the composition of a typical transaction participant's portfolio and, as such, is a property of the portfolio of the investor into the subject asset (composed of 1..n investments $s$ ) and not that of a particular subject asset, we introduce our averaging procedure for period $i$ :

$$
\sum_{s=1}^{n} P V_{s} \cdot \prod_{j=1}^{i}\left(1+v_{s}(j)\right)+\sum_{s=1}^{n} N O I_{s} \cdot \prod_{j=1}^{i}\left(1+u_{s}(j)\right)=\sum_{s=1}^{n} P V_{s} \cdot \prod_{j=1}^{i-1}\left(1+v_{s}(j)\right) \cdot\left(1+r_{s}(i)\right)
$$

Finally, to infer from Expression (2.10) $r(i)$-- a forecast of the representative portfolio discount rate related to period $i$-- we substitute individual asset-specific variables denoting the growth of both the

\footnotetext{
10 Cf. I. Fisher's quote: “A person's time preference...depends theoretically on the size, time shape and probability (as looked at in the present) of ... entire collection of income elements as we may picture them stretching out into the entire future." (Irving Fisher "The Theory of Interest" (1930) (II.IV.23))
} 
price and NOIs (marked by subscript $s$ ) with their portfolio-weighted averages. Thus, by using averages, we avoid the need to keep in mind all chains of individual growth variables (subscripted with s) so that our further modeling becomes easier on the portfolio level.

The following notation is used in averaging:

$$
\prod_{j=1}^{i}(1+v(j))=\frac{\sum_{s=1}^{n} P V_{s} \cdot \prod_{j=1}^{i}\left(1+v_{s}(j)\right)}{\sum_{s=1}^{n} P V_{s}},
$$

(note that $v(j)$ is just a portfolio representative average for growth in price levels likely to be observed in Year $j$ for assets comprising the portfolio). By the same token:

$$
\prod_{j=1}^{i}(1+u(j))=\frac{\sum_{s=1}^{n} N O I_{s} \cdot \prod_{j=1}^{i}\left(1+u_{s}(j)\right)}{\sum_{s=1}^{n} N O I_{s}}
$$

It is possible to prove that Expression (2.10) can be quite precisely solved for the year-contingent portfolio discount rate $r(i)$ in the following way:

$$
r(i)=\frac{R \cdot \prod_{j=1}^{i}(1+u(j))}{\prod_{j=1}^{i-1}(1+v(j))}+v(i)
$$

where $v(j)$ and $u(j)$ - are, respectively, the forecast averages of the growth in prices and incomes expected for assets constituting the portfolio over period $j$ (either synthetically derived, as shown, from the forecasts of separate data for the respective assets in the portfolio or suggested aggregately by an analyst); $R$ - is the portfolio yield ratio projected for the portfolio for period 1 . It can be approximated by the current yield ratio:

$$
R=\frac{\sum_{s=1}^{n} N O I_{s}}{\sum_{s=1}^{n} P V_{s}}
$$

Thus, we find that the future discount rate for period $i$ depends on the current portfolio yield ratio and the cumulative expected rates of growth in prices and incomes for assets comprising the portfolio up until, and including, period $i$.

To avoid confusion with the marking of intervals (taking into account that $u(1)=0$ ), we can transform Formula (2.13) as follows:

$$
r(i)=\frac{(1+u(i)) \cdot R \cdot \prod_{j=2}^{i-1}(1+u(j))}{(1+v(1)) \cdot \prod_{j=2}^{i-1}(1+v(j))}+v(i)
$$

Formula (2.15) may look cluttered, but it is a general-case discount-rate formula and, luckily, upon certain simplifying assumptions, can be made less off-putting. For example:

a) If it is possible to assume that the future portfolio-related rates of growth in prices and incomes for its assets are likely to be invariable over a number of periods up until (i), e.g. that they are not subjected to wide fluctuations, Formula (2.15) can be simplified in this way:

$$
r(i)=\frac{R \cdot(1+u)^{i-1}}{(1+v)^{i-1}}+v
$$


where $v$ and $u$ are the uniform (or "averagely-representative-of-the-future") rates of growth in prices and incomes (respectively) anticipated for the overall portfolio over the periods $1 \ldots i$. $r(i)$ - is the forecast of the (portfolio) discount rate for period $i$.

b) if the assumption above is untenable, but we expect the prices and incomes for the portfolio to move in the lockstep $(v(i)=u(i))$, the following simplification is true:

$$
r(i)=\frac{(1+v(i)) \cdot R}{(1+v(1))}+v(i)
$$

c) And, finally, if both assumptions are held reasonable $(v=u)$, the following will apply:

$$
r=R+v \text {. }
$$

By marking the discount rate in (2.18) as $r$ instead of $r(i)$ we stress the fact that the portfolio discount rate is expected to be constant over the entire interval of $1 . . . i$. periods (such an assumption is indeed very common in DCF modelling practices).

Thus, we have presented a Transactional Asset Pricing Approach (TAPA) framework to determine discount rates for the future, which is suitable for establishing the values-in-exchange of various assets, especially the illiquid ones (see MiCHALETZ, ARTEMENKOV, ARTEMENKOV 2007).

This discount rate framework can be helpful in itself, for it provides professional valuers with a convenient and quantifiable set of factors that primarily impact the formation of discount rate expectations, and Professional Valuers are often called upon by valuation standards to predict future discount rates, for example when they deal with Mortgage lending value $(M L V)$ estimations for real property (TEGoVA (2016)).

For us, the outlined approach to discount rates will be immediately important as we employ it in our comments and observations on asset valuation techniques, which we shall discuss in the next Section.

Below are listed some of the findings resulting from the above discussion:

1. Discount rate characterizes the composition of a typical subject asset investor's portfolio (i.e. subject assets' exchange circumstances), it is usually not a property of the subject asset per se ${ }^{11}$.

2. Yield ratio is the measure of expected income yield (for example, maturity yields for bonds or dividend yields for stocks) pertaining to the investor's portfolio in the first period after the valuation date. While the subject asset is often presumed to be an illiquid asset (or one valued in the context of an inefficient market ${ }^{12}$ ), the investor's portfolio might consist of both liquid and/or illiquid investments. Valuers should reflect on the composition of the portfolios of most likely buyers/sellers of the subject asset (the Market value basis of valuation), or on the composition of portfolios of its specific buyers/sellers (the Equitable value basis). In the area of illiquid assets valuation, it is not always possible to fall back on any normative theory of portfolio compositions.

3. As a limiting case, discount rate is equal to the yield ratio if it is reasonable to assume that prices and incomes for the portfolio components will stay put over time $(v=u=0)$. If the anticipated annual rates of change in income are greater than the forecasted rates of price appreciations, i.e. if $u>v$ for the portfolio, then overall rates of return/discount rates will tend to increase over time. Conversely, if the change in income is slower than the portfolio value change, i.e. when $u<v$ - the rates of return and discount rates will decrease. If both move in unison $(u=v)$ - the portfolio rates of return will be unchanged (remain constant) over time.

\footnotetext{
11 For example, there is hardly any need to incorporate in the discount rates such a universe of often unquantifiable factors as manifold "company-specific risks". These factors impact the growth prospects of a particular entity and, as we have shown above, should not be commingled with the "metric" of discount rates representing the expected economic performance of a likely subject asset investor's portfolio. We believe such a recurring sentiment is reiterated within The International Valuation Standards (IVSs) and European Valuation Standards (EVSs), which state that discount rates should be "market-derived" (as opposed to being "built-up" with the consideration of subject asset-specific features). The importance of proper analysis and appreciations of risk-contexts in valuation practice has been also emphasized in CICHULSKA and WISNIEWSKI (2017).

12 Obviously, on efficient markets, by definition, there is no need for the functions of professional valuers, as the entire market information set is presumed to be known, in equal measure, to all market participants (SLEE 2004).
} 


\section{Sense and meaning of the DCF and income capitalization models according to the transactional asset pricing approach}

This section employs the transactional asset pricing approach (TAPA) to formulate novel approaches to the derivation of some conventionally-used capitalization models under the income approach to valuation, e.g. Gordon, Inwood and Ring models, plus review - from a new angle -- the assumptions underlying the direct (income) capitalization format. An attempt is also made to develop a simple adjustment to the direct income capitalization format to make its application more in line with the transactional asset pricing approach principles.

So, reverting to the question of asset pricing models within the income approach, it should be remembered that the value-in-exchange of a subject asset depends on the (investor's) portfolio yield ratio and the anticipated net operating income NOI generated by the (subject) asset in the first period after the purchase transaction, as well as on the subject asset-specific rates of change in its future value and NOIs. Thus, Expression (1.5) can be re-written as:

$$
P V=\sum_{k=1}^{n} \frac{N O I \cdot \prod_{i=2}^{k}\left(1+u^{o}(i)\right)}{\prod_{i=1}^{k}(1+r(i))}+\frac{P V \cdot \prod_{i=1}^{n}\left(1+v^{o}(i)\right)}{\prod_{i=1}^{n}(1+r(i))},
$$

where $u^{o}$ and $v^{o}$ are the subject asset(object)-specific rates of change in its future NOIs and price, respectively. These should not be confused with $u$ and $v$, which reflect similar rates of change, but those likely to be observed for the presumed investor's portfolio. The latter rates are implicitly incorporated into (3.1), since the discount rates $r(i)$ included in (3.1) are inserted from (2.15) or (2.16), where they are based on the future portfolio-related growth rates $u$ and $v$ as discussed in the previous section.

Assuming that the rates of change in NOIs and prices for a specific subject asset $\left(u^{o}\right.$ and $\left.v^{o}\right)$ in all probability will not fluctuate too much period-to-period, we can simplify Expression (3.1) above in this way:

$$
P V=\sum_{k=1}^{n} \frac{N O I \cdot\left(1+u^{o}\right)^{k-1}}{\prod_{i=1}^{k}(1+r(i))}+\frac{P V \cdot\left(1+v^{o}\right)^{n}}{\prod_{i=1}^{n}(1+r(i))}
$$

Solving (3-2) for the sought value-in-exchange of the subject asset, $P V$, we get:

$$
P V=\frac{\sum_{k=1}^{n} \frac{N O I \cdot\left(1+u^{o}\right)^{k-1}}{\prod_{i=1}^{k}(1+r(i))}}{1-\frac{\left(1+v^{o}\right)^{n}}{\prod_{i=1}^{n}(1+r(i))}} .
$$

This can be regarded as the basic pricing equation in the transactional asset pricing approach (TAPA) framework. Indeed, in fairness, it is nothing other than the DCF format expressed mathematically. The discount rates $r(i)$ contained there are determined by running Formula (2.16).

Thus, asset-specific features/risks are implied in TAPA in the choice of asset-specific factors of growth $u^{o}$ and $v^{o}$. The TAPA approach is primarily growth-oriented: the locus of asset-specific features in it is in the growth factors $\mathcal{u}^{0}$ and $v^{o} .{ }^{14}$

\footnotetext{
13 This formula has been operationalized by authors as a MS Excel spreadsheet and is available as an attachement to this manuscript found here https:/ / drive.google.com/file/d/0B8hVnKfTz9_2NldEYnRIX21DMk0/view 14 According to TAPA, asset-specific risks for illiquid assets are of the nature of growth differentials in values and incomes manifested in the investor's reference market (i.e. in his portfolio) vis-a-vis the subject asset. If no difference is elicited or is likely to persist into the future, it is unreasonable to introduce any asset-specific risks into the pricing, no matter how outwardly different the subject asset and similar assets in the portfolio (reference market) happen to be. In practical terms, "risks" in the form of a range of possible deviations for input parameters in the formulas developed above can be considered, for example, by running Monte-Carlo (e.g. Crystalball@ ) simulations.
} 
How does the TAPA basic pricing equation (3.3) relate to the plethora of methods (e.g. the Gordon growth model, Inwood and Ring models) now much used in the income capitalization approach? It will be shown that the basic pricing equation can be simplified into any of these models under a certain set of assumptions. We will proceed to describe these assumptions, so that in the end we shall be able to integrate the general TAPA model with all the popular methods of the income approach to valuation, including the direct income capitalization format.

\subsection{Income capitalization formats}

\subsubsection{Direct income capitalization}

Running (3.3) with the discount rates calculated under (2.16), indicates that when the rates of price/income change for subject asset and the reference investment portfolio/market are equal between themselves (i.e. the subject asset lacks of any asset-specific risks: $\left(u=u^{o}, v=v^{o}\right)$, the market value of the asset is static over the time and equals to the quotient with the NOI for the first period in its numerator and the market yield ratio $R$ (from (2.14)) in the denominator. In other words, if the valuer feels confident that the rates for "synchronous" subject asset vis-à-vis the reference portfolio/market will stay in conjunction $\left(u=u^{o}, v=v^{o}\right)^{15}$, he can justify an application of the direct capitalization of net operating income:

$$
P V=\frac{N O I}{R} \text {, }
$$

where NOI -is the anticipated net operating income generated by the subject asset in the first period after the considered transaction; $R$ - is the yield ratio likely to be observed in the reference portfolio/subject's market over the first forecast period (Formula 2.14) ${ }^{16}$.

Formula (3.4) is the case of what, in Professional property valuation, is called the direct income capitalization technique whereby subject property is valued by dividing its first-period NOI by the reference "yield". This commercial property valuation technique is very wide-spread, especially in the Commonwealth countries (SAYCE et al., 2016). TAPA approach strictly reduces to it under the assumptions just outlined.

Still practicing appraisers are often prone to draw artificial distinctions between the DCF methodology (the general case of which is presented in shorthand in Formula 3.2) and diverse income capitalization methods, including the direct income capitalization format (3.4). (e.g. see SAYCE et al. 2006) for an attempt to justify the distancing of "market-based" direct income capitalization technique from the "investment-based" DCF analysis). As we have just shown, and will show further, all particular income capitalization techniques/methods known under the rubric of income approach are strictly corollaries of the basic Formula (3.3) for deriving a value-in-exchange from discounted cash flows.

Inductively, we will illustrate this statement with some other reductions of the TAPA basic pricing equation (3.3) into well-known income capitalization formats (e.g. Gordon, Inwood, Ring) and then will offer a general income capitalization formula, which may be found to be of convenience in practical valuation applications.

\subsubsection{Gordon growth formula}

Under what set of assumptions does the basic pricing equation (3.3) transform itself into an expression similar to the famous Gordon formula ${ }^{17}$ ? These assumptions are as follows:

\footnotetext{
15 This assumption is characteristic of "non-depreciating" assets, moving in sync with the reference investment portfolio.

16 Sometimes the notion of "gross rental multiplier" is used to denote the yield $R$. But gross rental multipliers relate to the reference market, while $R$ has been discussed above as a property of the subject asset typical investor's portfolio. Under certain circumstances, especially for undiversified investors, the two can be numerically the same -- where all of the investor's investment media relate to the same market as the subject asset.

17 Though the Gordon formula has been known under this name for a long time, RUBENSTEIN (2003) traces the antecedent correct attribution of this formula to "The Theory of Investment Value", a 1938 volume by John Burr Williams. It should be mentioned, however, that despite the similarity of the mathematical expression obtained by us, our interpretation of the formula is different.
} 
1. Income and prices for the assets comprising a typical investor's portfolio move accordingly and are uniform for any number of forecast periods $(u=v)$. This also, according to (2.18), implies that the discount rate over the entire length of the forecast period remains constant and equals: $r=R+v$.

2. Net income and price of the subject asset are projected to move in synch with each other and invariably over time $\left(u^{0}=v^{o}\right)$.

Under these assumptions, Equation (3.2) takes on the following form:

$$
P V=\sum_{k=1}^{n} \frac{N O I \cdot\left(1+v^{o}\right)^{k-1}}{(1+r)^{k}}+\frac{P V \cdot\left(1+v^{o}\right)^{n}}{(1+r)^{n}}
$$

And, solving Equation (3.5) for $P V$, we obtain the Gordon formula:

$$
P V=\frac{N O I}{r-v^{o}}
$$

As can be observed, the presented assumptions are different from those that are put forward in traditional Gordon model deductions ${ }^{18}$, but the result - the formula itself - is identical. It should be noted, that as the TAPA makes clear and contrary to the conventional perception among valuers, the Gordon formula is applicable to both positive and negative rates of changes in prices and incomes of subject assets, and it is not necessary to assume that the "terminal" value of the subject asset should be neglected over time or be based on some future stream of income after the time the terminal value is estimated (as happens under the conventional assumptions for the Gordon formula). This is seeing as how one important thing flowing out of the TAPA assumptions is that the value of the subject asset that results from the Gordon formula is not dependent on the assumption of the perpetuity of a steadily growing income stream or some other assumptions, such as a fixed useful life or a holding period. Therefore, it is possible to apply the Gordon formula not only for the "perpetual income stream" premise of valuation as Gordon does, but to also extend it to cover other premises of valuation that account for a voluntarily-chosen finite holding period and terminal value at the end of it, as per TAPA assumptions.

Recalling that according to the assumptions of the Gordon formula in TAPA: $r=R+v$, we can rewrite the formula as:

$$
P V=\frac{N O I}{R+v-v^{o}} \text {. }
$$

If the subject asset is expected to perform worse than its typical investor's reference portfolio in terms of price/income growth, i.e. if $v>v^{o}$, its value-in-exchange will be smaller than the average price observable for assets forming the investor's reference market/portfolio, which should be calculated by direct capitalization. What is more, Formula (3.7) explains why it is hardly conceivable for the value of the subject asset to be negative (or tend to infinity): for this to happen, it is necessary for the difference between the growth of the subject asset and the reference portfolio/market growth $\left(v^{v_{-}} v\right)$ to be so great as to exceed R. When this is the case, it should be clear that the reference market is not correctly identified for such an extraordinarily dynamic asset, or such an asset is too sui generis to be identified with any relevant reference portfolio ${ }^{19}$ and forms a "portfolio" of its own.

\subsubsection{Other income capitalization models (Inwood and Ring)}

The basic premise of all income capitalization models is the possibility to immediately convert firstfuture-period, or currently observable, incomes into indications of a value-in-exchange. Since the firstfuture-period net operating income NOI in Equation (3.3) is a constant factor, it is possible to pull it out from under the summation sign $\left(\sum\right)$ and transform the equation into the following:

\footnotetext{
18 E.g. see https://en.wikipedia.org/wiki/Dividend_discount_model . An alternative derivation of the Gordon formula, which resembles the one proposed here, has also been developed independently of us in prof. L. Leyfer's Paper (LEYFER 2006)

${ }^{19}$ Indeed, it is becoming permissible (according to the IVSC) to view single-asset markets as such. Refer to p.4 b of the following IVSC letter: http:/ / www.ivsc.org/pubs/comment/2006may-cica.pdf).
} 


$$
P V=\frac{N O I}{1-\frac{\left(1+v^{o}\right)^{n}}{\prod_{i=1}^{n}(1+r(i))}}
$$

If we denote the ponderous denominator as a capitalization rate Ro (not to be confused with the yield ratio $R$ ), a very comely-looking shorthand for all income capitalization models is obtained:

$$
P V=\frac{N O I}{R o} .
$$

\subsubsection{Inwood Framework - Simple and Extended}

In the Inwood capitalization model ${ }^{21}$, the capitalization rate $R o$ is intentionally, and for the purposes of representability, further subdivided into two components: the rate of return (discount rate) and the capital recovery rate. Thus:

$$
R o=r+F 3(n, r)
$$

where $F 3(n, r)=r /\left((1+r)^{n}-1\right)$ - is the capital recovery (return-of-capital) rate calculated in accordance with the third money function (otherwise known as the sinking fund factor (SFF)); $n$ - is the useful life of the subject asset.

As we can see, the Inwood capitalization model is different from the unsimplified DCF methodology, such as the one found in (3.3), but in form and assumptions, and not substantively. What are the Inwood assumptions?

1. Net income and prices in the investor's reference portfolio change with the constant and synchronous rate of change over the forecast period $(u=v)$.

2. Net income derivable over the holding period from the subject asset is constant $N O I_{k}=N O I=$ const, meaning that its rate of change is zero $\left(u^{o=0}\right)$;

3. The terminal value of the subject asset at the end of its useful life (holding period) (after the $n$-th year) is zero (refer to Formula (3.5))

After these assumptions are put into Formula (3.8), we arrive at the Inwood formula:

$$
P V=\frac{N O I}{r+F 3(n, r)} \text {. }
$$

If it is possible to suggest an estimated deterioration (different from zero) in the value of the subject asset at the end of its holding period or useful life, the "extended" Inwood formula can be derived. Substituting $(1-V)$ for $\left(1+v^{o}\right)^{n}$ in expression (3.8), where $V$ - is the deterioration in the value of the asset at the end of the holding period (in the $n$-th year), and assuming, as before, that growth in the net income is inexistent $\left(u^{o}=0\right)$, that is that:

$$
P V=\sum_{k=1}^{n} \frac{N O I}{(1+r)^{k}}+\frac{P V \cdot(1-V)}{(1+r)^{n}},
$$

after certain transformations this formula can be rewritten as follows:

$$
P V=\frac{N O I}{r+V \cdot F 3(n, r)} .
$$

This expression (3.13) is nothing other than the extended Inwood formula for income capitalization.

Under the assumptions above, calculations according to Formulas (3.8), (3.12) and (3.13) will lead to exactly the same results.

\footnotetext{
20 This formula has been operationalized by authors as a MS Excel spreadsheet and is available as an attachement to this Paper https://drive.google.com/file/d/0B8hVnKfTz9_2NldEYnRlX21DMk0/view

${ }^{21}$ For extended coverage of the Inwood model and other income capitalization methods, as they are traditionally used, see (FRIEDMAN, ORDWAY 1989).
} 


\subsubsection{Ring model}

There exists yet another model of income capitalization: the Ring method.

Assumptions implied in this model differ somewhat from the assumptions in Inwood:

1. The terminal value of the subject asset at the termination of the forecast period is considered to be zero.

2. Net incomes from the asset over the forecast period are expected to decline linearly in such a way that each successive income $N I_{i}(i=1 \ldots n)$ depends on the discount rate and the expected first-future-period income $\mathrm{NOI}=\mathrm{NOI}_{1}$ :

$$
N O I_{i}=N O I \cdot\left(1-\frac{\frac{r}{n}}{r+\frac{1}{n}}(i-1)\right) .
$$

For example, if the discount rate is assumed to be at $12 \%(r=0.12)$ and the projection period $n=4$ years, while net income for the first period is projected to constitute the amount of $\$ 370: N O I=N O I_{1}=$ 370 , the following incomes for successive periods are implied: $\mathrm{NOI}_{2}=340, \mathrm{NOI}_{3}=310, \mathrm{NOI}_{4}=280$.

The Ring model has been set out below:

$$
P V=\frac{N O I}{r+\frac{1}{n}}
$$

Discounting the cash flows projected in the paragraph above with the discount rate of $12 \%$, as we do under the DCF analysis when the terminal value is 0 , and capitalizing the first-future-period NOI of 370 in accordance with the Ring formula (3.15), the denominator there being $0.12+0.25=0.37$, results in exactly the same current exchange value of $\$ 1000$.

The Ring method is often used by appraisers because of its simplicity. However, it is unlikely that net incomes from subject assets will follow exactly the same patterns as those imputed by the underlying assumptions of the Ring formula.

For ease of reference, the assumptions under which the particular income capitalization models derive from the TAPA basic pricing equation (3.2) are presented in Table 1.

Table 1

Subject property assumptions under which the described income capitalization models are valid

\begin{tabular}{ccc}
\hline Model & Net income over time & $\begin{array}{c}\text { Terminal value at the end of the } \\
\text { projection period (n-th year) }\end{array}$ \\
\hline $\begin{array}{c}\text { Direct income } \\
\text { capitalization }\end{array}$ & $\begin{array}{c}\text { Changes synchronous with } \\
\text { incomes in the reference market } \\
u^{0}=u\end{array}$ & $\begin{array}{c}\text { Changes synchronous with prices on } \\
\text { the reference market } \\
v^{o}=v\end{array}$ \\
$P V=\frac{N O I}{R}$ & $N O I \cdot\left(1+v^{o}\right)^{i-1}$ & $P V \cdot\left(1+v^{o}\right)^{n}$ \\
$P V=\frac{N O I}{r-v^{o}}$ & \\
\hline Gordon & \\
\hline Constant & \\
\hline$r+F 3(n, r)$ & \\
\hline
\end{tabular}




\begin{tabular}{ccc}
\hline Inwood - extended & Constant & $P V \cdot(1-V)>0$ \\
\hline Ring & Decreasing: & $=0$ \\
$P V=\frac{N O I}{r+\frac{N}{n}}$ & $N O I_{i}=N O I \cdot\left(1-\frac{\frac{r}{n}}{r+\frac{1}{n}}(i-1)\right.$,
\end{tabular}

\section{Source: Own study.}

It is clear that each of the income capitalization models described has its own set of rather restrictive assumptions.

In the next subsection, we develop an income capitalization model that is believed to be more general and, therefore, convenient for practical use by valuers.

\subsubsection{Proposed income capitalization model (the "quick" income capitalization model)}

Assuming that the price and income growth rates for the subject asset and its reference investor's portfolio/market are time-invariant and equal to some average representative magnitudes, i.e. that $u(i)=u, v(i)=v, u^{o}(i)=u^{o}, v^{o}(i)=v^{o}$, Equation (3.3), accounting for the discount rate formula (2.13), can be expanded as:

$$
P V=\frac{N O I \sum_{k=1}^{n} \frac{\left(1+u^{o}\right)^{k-1}}{\prod_{i=1}^{k}\left(1+R \frac{(1+u)^{i-1}}{(1+v)^{i-1}}+v\right)}}{1-\frac{\left(1+v^{o}\right)^{n}}{\prod_{i=1}^{n}\left(1+R \frac{(1+u)^{i-1}}{(1+v)^{i-1}}+v\right)}}=\frac{N O I}{R} \cdot K_{p},
$$

where $K_{p}$ - is a (multiplicative-form) shorthand adjustment factor to the direct income capitalization model (3.4).

This format, which combines the direct income capitalization technique with an adjustment factor - to make the income capitalization more conformable to TAPA's DCF basis - can be considered to be a more general and less restrictive format compared to the other income capitalization models described above 22 .

Solving (3.16) for an unknown value of the adjustment factor $K_{p}$, we receive:

$$
K_{p}=\frac{R \sum_{k=1}^{n} \frac{\left(1+u^{o}\right)^{k-1}}{\prod_{i=1}^{k}\left(1+R \frac{(1+u)^{i-1}}{(1+v)^{i-1}}+v\right)}}{1-\frac{\left(1+v^{o}\right)^{n}}{\prod_{i=1}^{n}\left(1+R \frac{(1+u)^{i-1}}{(1+v)^{i-1}}+v\right)}} .
$$

Decomposing (3.17) into the first-order-derivative Taylor series in the neighborhood of these salient zero-reference-point parameters: $\mathrm{R}=0.1 ; \mathrm{n}=5 . .60 ; \mathrm{u}=0 ; \mathrm{u}^{\mathrm{o}}=0 ; \mathrm{v}=0 ; \mathrm{v}^{\mathrm{o}}=0$ :

22 The idea for such a format was suggested to the authors by SLUTSKY (2016). 
$K_{p}=K_{p}(0,1 ; 5 \ldots 60 ; 0 ; 0 ; 0 ; 0)+\delta K_{p} / \delta R(0,1 ; 5 \ldots 60 ; 0 ; 0 ; 0 ; 0) \cdot(\mathrm{R}-0,1)+$

$+\delta K_{p} / \delta n(0,1 ; 5 \ldots 60 ; 0 ; 0 ; 0 ; 0) \cdot(\mathrm{n}-5 \ldots 60)+\delta K_{p} / \delta u(0,1 ; 5 \ldots 60 ; 0 ; 0 ; 0 ; 0) \cdot(\mathrm{u}-0)+$

$\delta K_{p} / \delta u^{o}(0,1 ; 5 \ldots 60 ; 0 ; 0 ; 0 ; 0) \cdot\left(\mathrm{u}^{\mathrm{o}}-0\right)+\delta K_{p} / \delta v(0,1 ; 5 \ldots 60 ; 0 ; 0 ; 0 ; 0) \cdot(\mathrm{v}-0)+$

$\delta K_{p} / \delta v^{o}(0,1 ; 5 \ldots 60 ; 0 ; 0 ; 0 ; 0) \cdot\left(\mathrm{v}^{o}-0\right)$,

where $\delta K_{p} / \delta R$ - is the first-order partial derivative of the adjustment factor function (3.17) with respect to the yield ratio (derivatives with respect to the other pricing parameters are denoted in a similar way);

Our estimates indicate:

$$
\begin{aligned}
& K_{p}(0,1 ; 5 \ldots 60 ; 0 ; 0 ; 0 ; 0)=1 \text {, } \\
& \delta K_{p} / \delta R(0,1 ; 5 \ldots 60 ; 0 ; 0 ; 0 ; 0)=0 \text {, } \\
& \delta K_{p} / \delta n(0,1 ; 5 \ldots 60 ; 0 ; 0 ; 0 ; 0)=0 \text {, } \\
& \delta K_{p} / \delta u(0,1 ; 5 \ldots 60 ; 0 ; 0 ; 0 ; 0)=-K_{u} \text { - see Table } 2_{L^{-}} \\
& \delta K_{p} / \delta u^{o}(0,1 ; 5 \ldots 60 ; 0 ; 0 ; 0 ; 0)=K_{u} \text {-see Table } 2_{L^{-}} \\
& \delta K_{p} / \delta v(0,1 ; 5 \ldots 60 ; 0 ; 0 ; 0 ; 0)=K_{v} \text { - see Table } 2_{L^{-}} \\
& \delta K_{p} / \delta v^{o}(0,1 ; 5 \ldots 60 ; 0 ; 0 ; 0 ; 0)=K_{v} \text { - see Table 2.: }
\end{aligned}
$$

\begin{tabular}{|c|c|c|}
\hline $\begin{array}{l}\text { Holding period duration, } \\
\text { periods/years }\end{array}$ & $K_{u}$ & $K_{v}$ \\
\hline 5 & 1.810 & 8.190 \\
\hline 10 & 3.725 & 6.275 \\
\hline 15 & 5.279 & 4.721 \\
\hline 20 & 6.508 & 3.492 \\
\hline 25 & 7.458 & 2.542 \\
\hline 30 & 8.176 & 1.824 \\
\hline 35 & 8.709 & 1.291 \\
\hline 40 & 9.096 & 0.904 \\
\hline 45 & 9.374 & 0.626 \\
\hline 50 & 9.570 & 0.430 \\
\hline 55 & 9.708 & 0.292 \\
\hline 60 & 9.802 & 0.198 \\
\hline
\end{tabular}

Table 2

Direct income capitalization adjustment factors

Source: Own study.

Having regard to these transformations, Formula (3.18) reduces to the following neat expression:

$$
P V=\frac{N O I}{R} \cdot\left(1-K_{u}\left(u-u^{o}\right)-K_{v}\left(v-v^{o}\right)\right)
$$

This is the proposed "quick income capitalization model".

Testing this model against the basic pricing equation (BPE) Formula (3.2) DCF benchmark results in the following error distributions: 


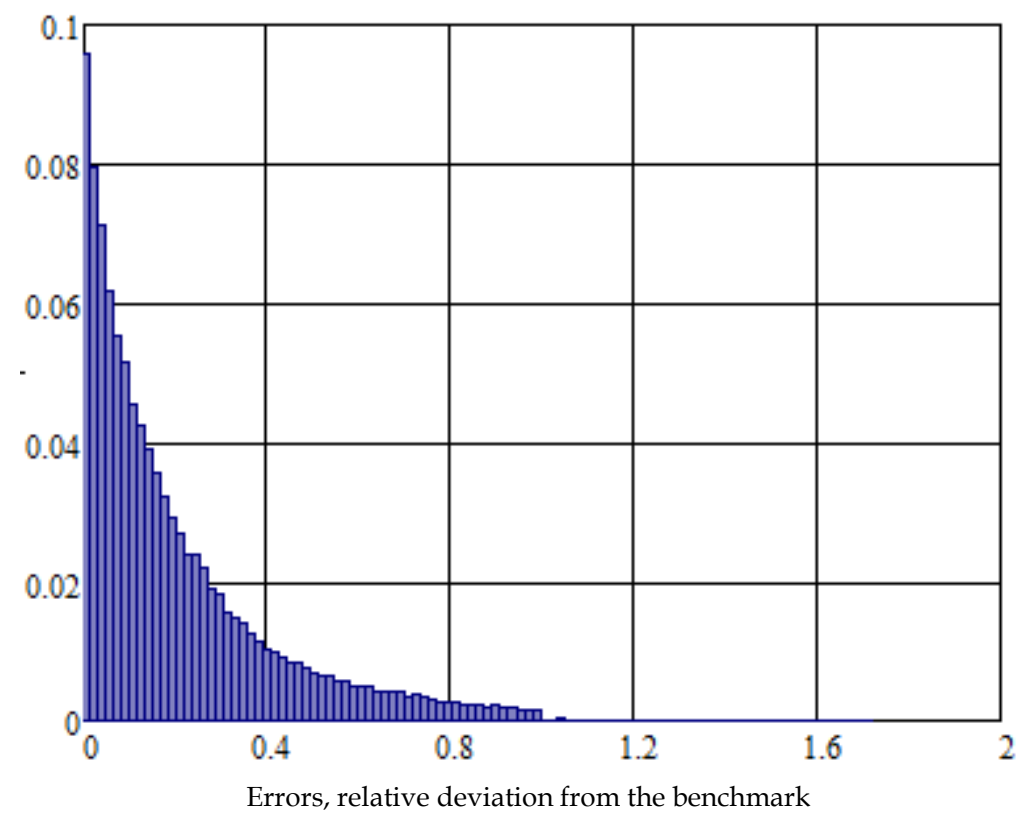

Fig. 1. Distribution of errors resulting from the "quick" formula (3.19), where the pricing parameters are drawn from the following ranges: $R=0.03 \ldots 0.13 ; u, v, u^{0}, v^{o}=[-0.05 \ldots 0.05]$. Source: own study.

As shown in Fig. 1, in $87 \%$ of trials, the errors of the "quick" formula do not exceed $40 \%$ of the DCF (Formula 3.2) benchmark estimates. Generally, the "quick" formula would work best (i.e. yield results most closely aligned with the BPE benchmark) when the income/value rates of change for the subject property approximate those for the reference portfolio: $u^{o} \rightarrow u, v^{o} \rightarrow v$. In such circumstances, the adjustment factor $K_{p}$ would be closer to unity and the attendant errors of approximation vis-à-vis BPE would be smaller.

For illustration purposes, below is a "quick" income capitalization approach worked example:

\section{Inputs:}

Net operating income $-\mathrm{NOI}=\$ 1$.

Yield ratio for the reference investor's portfolio $-R=0.09$.

Expected duration of the holding period for the subject asset $-n=10$ periods.

Anticipated rate of change for incomes in the reference investor's portfolio $-u=-0.016$ (average rate of decline in the portfolio income $-1.6 \%$ per period).

Anticipated rate of change for the income from the subject asset $-u^{0}=-0.019$ (average rate of decline in the subject asset income $-1.9 \%$ per period).

Anticipated rate of change in value of the reference investor's portfolio - $v=-0.012$ (average rate of value depreciation $-1.2 \%$ per period).

Anticipated rate of change in the value of the subject property - $v^{o=-0.013}$ (average rate of value depreciation $-1.3 \%$ per period).

An estimate derived under the quick income capitalization formula is as follows:

$\frac{1}{0,09} \cdot(1-3,725(-0,016-(-0,019))-6,275(-0,012-(-0,013)))=\$ 10,917$.

Cf. Benchmark DCF estimate (obtained under Formula 3.2): \$10,903

It appears that, in many instances, the performance of the proposed "quick" income capitalization model is superior to what can be expected from just randomly relying on the traditional and widespread direct income capitalization ("year's purchase") formats, such as those in SAYCE et al. (2006).

As a concluding caveat, and as seen from the distribution of errors even in the modified ("quick") income capitalization model, all income capitalization models are only valid and credible if they are employed with the full acknowledgement of their underlying assumptions, otherwise, and where no simplifying assumptions are possible, the application of Income capitalization can lead to gross distortions in value vis-à-vis the TAPA and DCF principles. 


\section{Conclusion}

We have shown a way to reconstruct the well-known valuation theory models, such as the direct income capitalization, Gordon, Inwood and Ring, on the basis of the transactional assets pricing approach (TAPA), which proceeds from its own principles (in Section 1) that are distinct from the traditional investment theory view. But the latter view essentially serves as a particular case within the more general TAPA approach that we have presented. The TAPA approach has found immediate applications for valuing illiquid assets (LEYFER 2006; ANDREWS 2011) and also lends itself to some noteworthy modifications. In particular, we have shown how to improve the direct income capitalization technique to make its estimates more aligned with the results obtainable under the TAPA basic pricing equation (i.e. the "quick" income capitalization method developed in this paper).

\section{References}

ARTEMENKOV A., MiKerin G. 2007, On the Distinctions Between the Perspectives of the Investment-Financial and Professional Valuations, Voprosi Ocenki Quarterly \#2, 2007 (published by the Russian Society of Appraisers www.mrsa.ru), pp. 27-39.

ARTEMENKOV A. 2017, Professional Valuation as a Field within Economic Measurements: Its Bases of Valuation and Other International Standardization Challenges (September 21, 2017), Working Paper, Available at SSRN: https:/ / ssrn.com/abstract=3040955.

ANDREWs D., 2011, Actuarial Methods for Valuing Illiquid assets, SOA Joint Risk Management Section publication, Society of Actuaries, 2011 https://www.soa.org/Files/Research/Projects/via-report12-2011.pdf.

CICHULSKA A., WISNIEWSKI R., 2017, Issue of the Risk in Literature, Real Estate Management and Valuation, vol. 25, no. 3, pp. 74-86.

Damodaran A., 2002. Investment Valuation: Tools and Techniques for Determining the Value of Any Aassets 2ed, John Wiley\& Sons, (the whole book is also available for free as e-text at: www.damodaran.com).

DEMPSEY M., 1996, Corporate Financial Management: Time to Change the Cost of Capital Paradigm?, Critical Perspectives on Accounting: Vol. 7, No. 6, pp. 617-63.

EKERN S. 2006, A Dozen Consistent CAPM-Related Valuation Models - So Why Use an Incorrect One? (November 29, 2006), NHH Finance \& Management Science Discussion Paper, No. 6/2006 Available at SSRN: http://ssrn.com/abstract $=968599$.

Jensen M., 1972, The Foundations and Current State of Capital Market Theory, Harvard Business School http:/ / papers.ssrn.com/abstract=350428).

FISHER I., 1930, The Theory of Interest: As Determined by Impatience to Spend Income and Opportunity to Invest It, New York: Macmillan.

FRIEDMAN J., ORDWAY N., 1989, Income Property Appraisal and Analysis, New York: Prentice Hall.

GalasyuK V., SOROKA M., 2002, Anthropological Approach to Determining Discount Rates (The GAD Concept as the Corollary of the CCF Concept), Галасюк Валерий, Сорока Мария, Галасюк Виктор Антропологический подход к определению ставки дисконтирования (GAD-концепция как следствие концепции ССF)//Государственный информационный бюллетень о приватизации.-2002.-№11.-C.57-60. (also available at :

http://www.galasyuk.com.ua/publications.html?lang=ru\#theme_4).

GALASYUK V., SOROKA M., 2002, The Notion of Economic Risk within the Conventionality Cash Flows Concept, (Галасюк Валерий, Сорока Мария, Галасюк Виктор, Понятие экономического риска в контексте концепции ССF//Вестник бухгалтера и аудитора Украины.-2002.-№15-16.-С.2634.) (also available at: http://www.galasyuk.com.ua/publications.html?lang=ru\#theme_4) .

GalasyUK V.V., 2016, Establishing Fair Value of Objects in Barter, Donation and Exchange Transactions, Art-Press, Dnepr 2016.

GARVEY G. T., 2001, What is an Acceptable Rate of Return for an Undiversified Investor?, Working Paper (September), Available at SSRN: http:// ssrn.com/abstract=281432.

LEYFER L., 2006, On the Direct Capitalization Methodology and Generalized Inwood Model, Voprosi Ocenki Quarterly (published by the Russian Society of Appraisers), №3, 2006. p. 47-59 (also available at http://www.labrate.ru/leifer/lev_leifer_article-model_inwood.htm).

LeYFer L., DubOvKIN A., 2003, Applicability of CAPM for Determining Discount Rates on Russian Investment Markets, stable URL http://pcfko.ru/research5.html\#1. 
LinTNER J., 1965, Security Prices, Risk, and Maximal Gains From Diversification, The Journal of Finance, Vol. 20, No. 4, pp. 587-615. Stable URL:http://links.jstor.org/sici?sici=0022$1082 \% 28196512 \% 2920 \% 3$ A4\%3C587\%3ASPRAMG\% 3E2.0.CO\%3B2-U.

MERCER C., 2004, The Integrated Theory of Business Valuation: Valuing Shareholder Cashflows, Peabody publishing, Memphis (ch.7).

Michaletz V., 2002, Discount Rate in Valuation Practice, Voprosi Ocenki Quarterly (published by the Russian Society of Appraisers www.mrsa.ru), №3, p.35.-42.

MichaletZ V., 2005, Discount Rates and Income Approach Methodologies, Voprosi Ocenki Quarterly (published by the Russian Society of Appraisers www.mrsa.ru), №1, 2005, p. 3-19.

Michaletz V., 2005. The Principles of Portfolio Averaging in Market Valuations, Voprosi Ocenki Quarterly №4, p.53-59 (published by the Russian Society of Appraisers www.mrsa.ru).

MichalETZ V., ARTEMENKOV A., ARTEMENKOV I., 2007, Income Approach and Discount Rates for Valuing Income-Producing Illiquid Assets - Outlines of New Framework: Revisiting the Concepts in Income Approach and Developing the Model of Illiquid Assets Transactional Pricing, Icfai Journal of Applied Finance, December, Proceedings of the Icfai University and the University of Philadelphia V International Conference on Business and Finance, Hyderabad (India), Available at SSRN: https://ssrn.com/abstract $=996016$.

Michaletz V., ARTemenKov A., 2008, Discounted Cash Flows Analysis and the Discounting Procedure in Market Valuations - How We Understand Them: A Brief Conceptual Note for Professional Valuers, January Available at SSRN: https:/ / ssrn.com/abstract=1090069 orhttp:// dx.doi.org/10.2139/ssrn.1090069.

Miller M.H., Modigliani F., 1961, Dividend Policy, Growth and the Valuation of Shares, The Journal of Business, Vol. 34, pp. 411-433.

MuCZYŃSKI A., 2015, An Integrated Approach to Real Estate (Portfolio) Management, Real Estate Management and Valuation, Vol. 23, No. 2, pp. 5-16.

PRATT S., ReILly R., SCHWEIHS R., 2000, Valuing a Business: Valuation of Closely-held Companies, Textbook (4th edition); New York: McGraw-hill.

Rubenstein M., 2003, Great Moments in Financial Economics: 1 Present Value; in the The Journal of Investment Management (1 Quarter 2003), (also available at: www. in-themoney.com/pages/author.htm).

SAYCE S., SMITH J. et al., 2006, Real Estate Appraisal: from Value to Worth, Blackwell publishing, Oxford.

SLEE R., 2004, Private Capital Markets: Valuation, Capitalization, and Transfer of Private Business Interests, Hoboken: John Wiley \& Sons.

SLUTKSY A., 2016, Long-term Trends on the Commercial Property Market of Moscow: Ex-post Analysis, RWAY Bulletin, \#251 (February), pp. 140-152.

SHARPE W., 1964, Capital Assets Prices: The Theory of Equilibrium under Conditions of Risk, The Journal of Finance, Vol. 19, No. 3, pp. 425-442.

TRAYNOR J., 1962, Toward a Theory of Market Value of Risky Assets, Unpublished manuscript (available at: http:/ / papers.ssrn.com/sol3/papers.cfm?abstract_id=628187)

InStiTUTIONAL WorK (1989), “The Appraisal of Real Estate”, The Appraisal Institute Students' Bound Volume, tenth edition, 1989, p. 422.

IVSC (2017), The International Valuation Standards 2017 (also available at: www.ivsc.org)

TEGoVA (2016), The European Valuation Standards 2016 (TEGoVA - available at www.tegova.org). 